\title{
Comparing electronic monitoring regimes: Length, breadth, depth and weight equals tightness
}

\section{Anthea Hucklesby (D)}

University of Leeds, UK

\section{Kristel Beyens (D)}

Vrije Universiteit Brussel, Belgium

\section{Miranda Boone}

University of Leiden, The Netherlands

\begin{abstract}
This paper compares the use of electronic monitoring in three European jurisdictions Belgium, England and Wales and the Netherlands. It suggests that rates of use, the accepted method of comparison in relation to imprisonment and a proxy measure of 'punitiveness' provide a misleading picture when applied to electronic monitoring. This paper transforms Crewe's concept of 'tightness' from a dimension of weight to encompass the overlapping elements of length, breadth, depth and weight to provide a framework for analysing how electronic monitoring regimes are designed to disrupt the lives of monitored individuals. Electronic monitoring regimes are diverse and 'tightness' varied as much, if not more, within as between jurisdictions. Comparisons of 'tightness' also inverted the scale of 'punitiveness' produced using rates of use.
\end{abstract}

\section{Keywords}

community sanctions, comparative penology, electronic monitoring, punitiveness, tightness

\section{Corresponding author:}

Anthea Hucklesby, School of Law, University of Leeds, Leeds, UK.

Email: A.L.Hucklesby@leeds.ac.uk 


\section{Introduction}

Traditionally, the use of penal measures in different countries has been compared using imprisonment rates (Walmsley, 2018). Imprisonment rates are often used as a proxy measure for punitiveness despite valid criticisms of this approach (Cavadino and Dignan, 2006; Crewe, 2015; Matthews, 2005; Pease, 1994). However, the widespread use of community sanctions and measures, ${ }^{1}$ including electronic monitoring (EM), means that this approach is misleading (Aebi et al., 2019; McNeill and Beyens, 2013). Significantly more individuals are subject to community sanctions than imprisonment in Europe (1.8 million compared with 1.23 million respectively in 2018) (Aebi and Tiago, 2019; Aebi et al., 2019); the pattern of use of community sanctions across Europe differs from imprisonment (Aebi et al., 2019); and statistics on the use of community sanctions are less reliable than imprisonment data (Aebi et al., 2015). Consequently, imprisonment rates, at best, provide only a partial picture of a country's approach to punishment and its relative punitiveness.

Rates have also been used to compare the deployment of community sanctions in different jurisdictions (Aebi et al., 2019). But this methodology does not take account of the range of community sanctions which are available, differences in the way in which sanctions are executed or important qualitative differences in community sanction regimes (McNeill and Beyens, 2013). This paper goes beyond the measurement of rates to compare one type of community sanction, EM, in three European jurisdictions - Belgium, England and Wales ${ }^{2}$ and the Netherlands - using qualitative data. It demonstrates that whilst measuring absolute numbers and rates of use places England on top of the punitiveness scale, taking account of a broader range of factors relating to EM regimes paints a different and more complex picture. The analysis highlights the need to look beyond rates of use of EM and community sanctions more broadly (and arguably prison too) in order to compare sanctions within and between countries, especially if these result in assessments of 'punitiveness'.

A diverse range of technologies are encompassed by the term of 'electronic monitoring'. This paper focuses on the use on wearable location monitoring technologies used to monitor the presence of individuals in particular places and/or inclusion/exclusion zones or track wearers' movements in real time or retrospectively by criminal justice systems. EM is available in nearly every country and is used at three stages of the criminal justice process - pre-trial, sentencing and post-release - as a standalone measure or to monitor compliance with other conditions. EM is already an important penal measure, and recent research suggests it will continue to grow and its prominence will increase, thereby making a significant contribution to the repertoire of penal sanctions in the future (Hucklesby et al., 2016).

The scale of EM use in the three jurisdictions studied in this paper is very different, although they all use EM across the criminal justice process. In terms of absolute numbers, England is one of the highest users of EM in Europe. 
On 31 March 2018, 11,167 individuals were subject to EM. Just over two-fifths $(43 \%)$ were subject to community sanctions with $25 \%$ on bail and $30 \%$ released from prison under Home Detention Curfew (HDC), a discretionary early release scheme. On 1 December 2017, around 1700 individuals were subject to EM in Belgium. More than four-fifths $(85 \%)$ were serving prison sentences on EM, over a tenth (14\%) were on EM pre-trial and a small number were serving an autonomous sentence. In the Netherlands, 616 individuals were subject to EM on 24 March 2018. Of these, a quarter (27\%) were serving prison sentences on EM (penitentiary programme) with nearly a fifth (18\%) serving a conditional sentence. A further quarter was subject to EM pre-trial $(24 \%)$ with a tenth $(9 \%)$ on conditional release from prison. Whilst these figures are not directly comparable, EM rates per 100,000 population reveal that England has the highest rate of use (19 per $100,000){ }^{3}$ Belgium has the second highest rate (15 per 100,000) with the Netherlands significantly lower at 4 per 100,000. According to quantitative measures, England would be categorised as the most punitive user, followed by Belgium with the Netherlands being considerably less punitive.

Having established a proxy scale of punitiveness, the remainder of this paper compares EM by focussing on qualitative factors relating to the design of regimes. We draw on the work of Downes (1988), King and McDermott (1995) and Crewe (2011) to construct a framework for comparing EM regimes which results in a more nuanced understanding of punitiveness as it relates to EM. Before this, we explore the concepts of length, breadth, weight and depth to provide a theoretical framework for our later comparative analysis. We suggest that Crewe's (2011) concept of 'tightness', i.e. the degree to which EM 'grips', takes hold of and disrupts the lives of wearers wrapping them in a 'web', provides a useful qualitative assessment of punitiveness in relation to EM and community sanctions as well as imprisonment. Significantly, however, we define 'tightness' as combining the dimensions of length, breadth, weight and depth rather than adopting Crewe's $(2011,2015)$ approach of conceptualising tightness an integral aspect of weight.

\section{Conceptualising EM regimes}

Prison regimes have been analysed and compared using the concepts of length, breadth, depth, weight and tightness (Crewe, 2009, 2011; Downes, 1988; King and McDermott, 1995). Length of incarceration differentiates regimes worldwide and is one way of comparing regimes, but it represents only one dimension of how they are constructed and experienced. Downes' (1988) comparative study of prison regimes in the Netherlands and England demonstrated that the length of incarceration failed to capture the essence of the differences between the two prison systems. He characterised English prison regimes as deeper and therefore more damaging and repressive than those of Dutch prisons. Initially, he conceptualised depth as the extent to which regimes were experienced as a 'psychological invasion' and 'the overall quality of life which the prison regime made possible or withheld' (Downes, 1988: 166). King and McDermott (1995) later suggested Downes' 
originally conception of 'depth', was better described as 'weight', i.e. the extent to which prison regimes are 'heavy and oppressive', bear down upon prisoners psychologically and are a 'weight on their shoulders' (King and McDermott, 1995: 89). In short, weight is about the burdens regimes place upon prisoners.

Downes (1992: 15) later redefined depth as 'the openness of the prison to life in the outside world' including contact with families and friends and taking part in 'normal' life activities. The more removed prisoners are from life outside of prison and the more their normal life activities are disrupted, the 'deeper' the prison regime. There is a complex relationship between depth and weight and prisoners at the deep-end of the prison system, i.e. maximum security long-term imprisonment, tend also to experience it as heavier (King and McDermott, 1995). What we take from Downes' analysis is that the extent to which a sanction, whether prison, $\mathrm{EM}$ or other form of community sanction, disrupts the normal activities of life is a useful way of comparing their aims and the experiences of those subject to them.

Crewe (2011) observed during his study of one medium secure UK prison that the nature of prison regimes had changed. The physical brutalising regimes identified by King and McDermott (1995) had been replaced by more subtle, less visible forms of control. Prisoners described new and different pains of imprisonment in addition to those originally identified by Sykes (1958). The first of these is uncertainty arising from discretionary governance, i.e. variability in the application of rules. As Crewe (2011: 513-514) describes the uncertainty about when coercive power might be used 'triggers and expands the psychological territory that power occupies ... [prison] lacks solidity and predictability, with actions and consequences unreliably connected'. The second pain of imprisonment is self-government, i.e. that prisoners are given the autonomy to decide their own destinies and made responsible for their actions and decisions. Prisoners are no longer able to simply do their time. Instead, prison is demanding, requiring prisoners to actively engage and work at their own confinement. Crewe (2011: 522) characterises this new regime as 'tightness' because 'it does not so much weigh down prisoners and suppress them as wrap them up, smother them and incite them to conduct themselves in particular ways'. Tightness is analogous to a web requiring prisoners to self-regulate, police their own behaviour and conform when the boundaries and rules are unclear. Regimes 'grip' individuals because they have considerable leverage over them. Rules are not oppressively enforced but infractions are recorded for use when deemed necessary. 'Soft' power reigns. Only when it fails, does 'hard' power, i.e. authority, step in to ensure 'that opportunity, support and self-correction are grasped and pursued appropriately' (Crewe, 2009: 448). As Crewe (2011: 456) notes 'Where prisoners fail to regulate themselves appropriately, the prison's authoritarian face reveals itself through ... punishments'.

These concepts, used to describe prison regimes from the point of view of prisoners, also assist us to understand and compare EM regimes. This is not to underestimate the importance of differences between prison and EM and community sanctions. Prisons remove individuals from their communities and constrain, 
structure and regulate their lives to a much greater extent than community sanctions. It is also true that not all of Sykes's (1958) five original pains of imprisonment apply to community sanctions and the degree of deprivation experienced is likely to be qualitatively different to that experienced by prisoners. Different pains of 'probation' (Durnescu, 2011; Hayes, 2015), EM (Payne and Gainey, 1998; Vanhaelemeesch, 2015; Vanhaelemeesch et al., 2014) and 'freedom' (Shammas, 2014) have also been identified. Nevertheless, the changes in regimes and the nature of power in prisons described by Crewe (2011) have shifted some of the methods of control exerted within prisons nearer to those on which community sanctions have always relied, i.e. self-regulation, engagement and positive obligations.

We are also aware that by borrowing concepts from prison studies, we might reinforce the notion that EM is little more than house arrest, imprisoning people in their own homes. But it cannot and does not incapacitate individuals in the same way as prison. Wearers remain in the community, often living at their usual residence with significant others. They have freedom of movement within the confines of the restrictions placed upon them. There is nothing which physically prevents individuals from interfering with or removing the equipment (Hucklesby, 2009). However, the authorities will know about the non-compliant behaviour and unwanted consequences may follow. Compliance is a requirement but wearers ultimately have a choice about whether or not to comply (Hucklesby, 2009). EM then requires self-regulation, albeit supported and monitored by technological tools.

Whilst we think that wearers' experiences of EM are vital to assessing the breadth, depth, weight and therefore, tightness, this is not our aim here. Instead our focus is on the legal, policy and practice frameworks which structure EM regimes. An analysis of the legal and policy framework in which EM operates, i.e. how the regime is intended to operate, is necessary to understand how it does operate and how it is experienced by those subject to it. Understanding the framework within which EM operates is crucial to any attempt to assess and compare EM (and community sanction) regimes. This is because the law, regulations, policies, procedures and practices frame the ways in which regimes are experienced and the frameworks are diverse between and within countries as a result of the many different modalities of EM. Therefore, our analysis will focus on the ways in which the EM regimes are designed to impact upon the daily lives of individuals subject to EM. Some of the elements we discuss may have been designed intentionally for a specific purpose whilst others may have unforeseen consequences and have different and sometimes contradictory effects.

For our purposes, depth is defined in terms of the ways in which regimes are designed to curtail the everyday lives of wearers which includes three categories of activities: 'basic or survival' (eating, food shopping, care responsibilities, visits to doctors, etc.); 'education/employment'; and 'leisure' (including Downes' concepts of recreational, informational and social). Weight is the burden EM regimes place upon individuals, i.e. how much regimes are designed to have a psychological impact on individuals. Breadth has been discussed by Cohen (1985) and others 
in terms of the dispersal of discipline thesis which highlights the ways in which community sanctions disperse discipline away from prisons into communities via 'net-widening', 'mesh thinning', 'blurring' and 'penetration'. We borrow Cohen's ideas to conceptualise breadth as the extent to which EM regimes penetrate the lives of wearers, blurring the boundaries between monitored and unmonitored lives, the range of activities which are affected and the extent to which the effects of the regime extend beyond the individuals being monitored to other people and locations. Like others, we believe that the relationship between length, depth, weight and breadth is complex and different aspects of EM regimes affect some or all of these dimensions simultaneously (see Figure 1). We think that 'tightness' (Crewe, 2011) is a particularly useful concept to explore how EM regimes are designed to impact upon the lives of wearers. We adapt Crewe's original concept of 'tightness' as an aspect of weight so that it captures the overlapping elements of regimes characterised by length, depth, weight and breadth. We suggest that these elements are mutually reinforcing making 'tightness' more than the sum of its parts. Crewe's notion of 'grip', i.e. the 'tightness' by which regimes take hold of individuals is particularly pertinent to EM regimes and we return to demonstrate

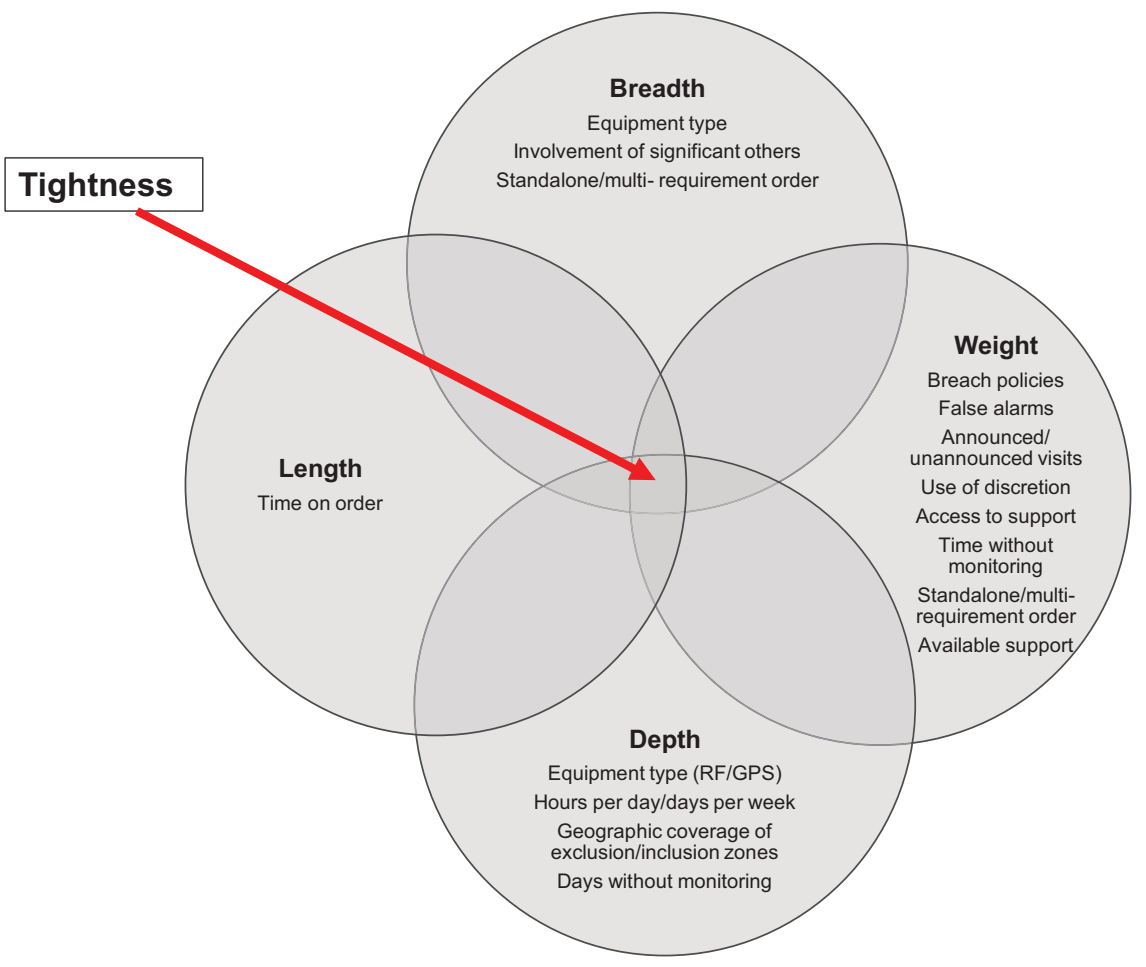

Figure I. Dimensions of tightness.

RF: radio-frequency; GPS: Global Positioning Systems. 
why in the conclusion. In the next section, we focus on four elements - equipment, intensity, intrusiveness and non-compliance and breach - to compare EM regimes in our three jurisdictions before drawing conclusions about differences in their 'tightness'.

\section{Comparing EM regimes in Belgium, England and the Netherlands}

\section{Equipment}

This section discusses the ways in which different types of equipment may exert different forms and levels of control over wearers. There are two types of location monitoring technologies: Radio-frequency (RF) and Global Positioning Systems (GPS). RF is used to monitor conditions (usually curfews) which require individuals to stay in a particular location/building for specified periods. RF technology works via a tag which is attached around the ankle and transmits signals to a monitoring centre, via a unit at the curfew address. If the tag and the monitoring box lose contact, a violation alert is triggered. RF technology is tried and tested and has a high degree of accuracy.

The second type of location monitoring uses GPS. The position of the tag, and hence the person, is tracked via the triangulation of the GPS signals. Location data are normally examined retrospectively or used to monitor exclusion/inclusion zones via electronically generated alerts. Curfews are also monitored by GPS. GPS devices are larger and heavier than RF devices and problems exist with poor signals and drift, i.e. the location of wearers is incorrect. The battery charging regime is also onerous requiring time and wearers to be proactive. Devices require daily charging for approximately two hours via a mains cable or portable charger fixed onto tags (which increases their already significant size and weight). A variety of ways are used to alert wearers to infractions of exclusion/inclusion zones and nudge them to charge devices including text messages, vibrations and telephone calls.

The dominant form of EM in two of our three jurisdictions is RF. In Belgium, around $86 \%$ of EM deployment uses RF with GPS being restricted to pre-trial use. The vast majority of EM uses RF technology in England. A national roll-out of GPS has been completed, but the use of GPS is predicted to remain relatively small. The Netherlands uses GPS much more. In 2018, 75\% of EM used GPS devices, a significant increase from $25 \%$ in 2014.

One area of contrast between RF and GPS technologies relates to the restrictions they monitor. RF monitors the presence of individuals in a relatively small contained area and records when they leave and return. By contrast, GPS technologies provide 'freedom' for individuals to go about their daily lives within any spatial restrictions imposed, although their movements are mapped and recorded continuously. However, the 'freedom' which is experienced under GPS is likely to be qualitatively different from 'unmonitored' freedom and may be 
premised on what the alternative is likely to be or is thought (Hudson and Jones, 2016). The impact of being 'watched' is also relevant to RF with studies suggesting that both the physical presence of the equipment and feelings of being 'watched' influence wearers' behaviour (Gacek, 2019; Hucklesby, 2009; Nellis, 2013).

RF data are collected continuously but only actively monitored during curfew hours. The data collected via GPS devices are much more detailed, pervasive and intrusive. The geographical data allow detailed pictures to be built up of wearers' habits, routines and associations. Anyone associated with locations visited by wearers have data collected about the frequency and duration of their contacts with wearers. This broadens the reach of monitoring beyond the individuals subject to the requirements.

\section{Regime intensity}

Whilst the equipment influences the 'tightness' of EM, the regime constructed around it is potentially more influential. In this section, we examine aspects of regime intensity. This is measured by length; depth, i.e. the extent to which it is designed to constrain wearers' daily activities; breadth, i.e. the extent to which it impacts upon others; and weight, i.e. how much of a burden it is. By studying these aspects of regime intensity, we begin to understand the 'tightness' of EM regimes.

$\mathrm{EM}$ is deployed differently in and between the three jurisdictions which results in different levels of intensity for wearers. In terms of the length, paradoxically, all three jurisdictions place no limit on the length of time EM can be used pre-trial, even though wearers are legally innocent. At the sentencing stage, maximum periods are prescribed in two of our jurisdictions. Autonomous sentences of EM can be imposed up to a maximum of 12 months in both Belgium and England, although no more than six months is the norm in England. England is the only jurisdiction to set a separate legal maximum for the use of EM when prisoners are released from prison early under HDC (135 days). However, there is no separate legal maximum when it is used to monitor licence conditions.

In Belgium, the maximum period of EM for those serving prison sentences of three years or less is 12 months. For those serving sentences of more than three years, EM may continue until the end of the sentence (Beyens and Roosen, 2016). In the Netherlands, EM can be imposed technically for a maximum of 10 years or life in serious cases, although the average time on EM is four months (Boone et al., 2016). EM is deemed to be an integral element of probation supervision and is not regulated separately by law. In these circumstances, wearers may be unaware when EM will end and/or what they need to do for it to be removed, creating uncertainty and potentially intensifying its 'grip'. Similar issues arise with Integrated Offender Management 'voluntary' schemes in England (Hudson and Jones, 2016). The use of EM under these schemes, which provide intensive supervision programmes for high-risk and/or prolific offenders, is not legally regulated. Individuals must therefore 'consent' to EM and as long as they do so may be subject to it for an indefinite duration. None of the jurisdictions prevent EM being used concurrently or 
consecutively for different purposes which may increase the period of use beyond legal maximums, when they exist.

A second area of difference in regime intensity is whether it is available as a standalone or part of a multi-requirement measure. Standalone use of EM requires wearers to comply with the requirement monitored by EM - usually curfews and nothing more. This approach limits the obligations on wearers and the impact on their lives, potentially reducing the intensity of the sanction and its 'tightness' (Hucklesby et al., 2016). By contrast, combining EM with other requirements, such as probation supervision and community service/unpaid work, may increase the 'tightness' of sanctions because the obligations are more numerous and require individuals to modify their lives to a greater extent (McNeill, 2018). However, multi-requirement orders may be experienced less tightly than standalone orders because the requirements are mutually supportive and loosen rather than tighten the 'grip'. Conversely, standalone orders may be experienced as 'tighter' because they require individuals to regulate their own behaviour without assistance from probation staff, thereby generating stress.

Our jurisdictions vary in terms of their use of standalone EM requirements. In England, a significant number of individuals are subject to EM as a standalone sanction. This includes around half of those subject to EM as a requirement of community sentences. In Belgium, three groups are subject to standalone EM (GPS bail, EM as an autonomous sentence and those serving prison sentences of up to three years). The remainder of those subject to EM in Belgium (i.e. those sentenced to prison for terms of over three years and which comprise around one-third of the daily EM population) are required to abide by curfew requirements and are supervised by Justice Assistants (equivalent to probation staff) or the police adding 'weight' to their sentences. Individuals are required to work or look for work/training and meet regularly with Justice Assistants, pay compensation to victims, attend programmes to tackle drug or aggression problems and have drug tests. In the Netherlands, the penitentiary programme requires wearers to spend at least 26 hours a week on daily activities (work and/or education). Although other uses of EM do not have this requirement, individuals are required to stay at home for 22 hours a day if they are not in education or employment (Boone et al., 2017). In England, curfew orders with EM are combined with other requirements in around half of the cases. Probation services manage these cases but do not necessarily 'supervise' them. Requirements may include unpaid work, attendance at accredited programmes or drug and/or alcohol treatment. The average number of requirements attached to these orders in England is between two and three, despite more being available (Ministry of Justice (MoJ), 2018).

A third element of EM intensity, which is a constituent part of 'depth' and 'weight', is the period of time individuals are confined during any one day. RF technologies are used mostly to monitor confinement but GPS technologies are also used to monitor curfews and/or exclusion/inclusion zones which are enforced for all or part of the day. For example, in Belgium, GPS technologies are used to monitor compliance with 24 hour curfew requirements for individuals awaiting trial. 
These wearers are completely reliant on others for their basic needs and cannot work or participate in education. This provides an example of the tightest form of EM in our three jurisdictions. It also illustrates how the intensity of the regime depends partly on the circumstances of wearers. Support and assistance from family and friends may reduce some of the 'weight' of EM regimes whilst at the same time increasing their 'breadth' by requiring the involvement of others in the execution of the order (Hucklesby, 2008; Vanhaelemeesch and Vander Beken, 2014).

The intensity of RF EM increases with the number of hours individuals are monitored. Importantly, the legislation in England sets out the hours of confinement, whereas in Belgium and the Netherlands, the hours of freedom are proscribed. England has the least intense EM regime at the sentencing and post-sentencing stages in this regard. Hours of confinement vary between 2-16 hours for community sentences and between 9-12 hours for HDC, although in practice, curfew hours are usually between 10-12 hours a day. Hours tend to apply seven days a week and remain unchanged during the lifetime of orders unless individuals' circumstances change (Hucklesby and Holdsworth, 2016). In the Netherlands, all EM modalities have the same number of hours of freedom between 2 and 17 hours (i.e. 7-22 hours of confinement). The number of hours of freedom is decided initially according to offenders' risk profile and becomes less restrictive over time (Boone et al., 2016). In Belgium, hours are less onerous for modalities other than bail but remain more restrictive than in England or in the Netherlands. Individuals serving prison sentences of up to three years have a minimum of four hours and a maximum of 12 hours freedom (i.e. 12-20 hours of confinement).

The underlying principle of EM hours in all of our jurisdictions is that curfews should impact predominantly upon 'leisure' time rather than basic/survival and working/education activities. This is most clearly seen in England where curfews are normally between 19.00 and 07.00 , and there is a principle that curfew hours should fit around working/education patterns and take into account caring responsibilities. In the Netherlands, curfew hours are longer at weekends than in the week reflecting an assumption that wearers have work or education commitments on weekdays and vary according to these commitments. The hours of freedom equalise at their highest point once wearers are deemed to be at the lowest risk level. Whilst Belgium also has less restrictive regimes of hours for those who work or who attend education, it is much more restrictive, affecting basic tasks for those who do not. For example, when not in work or education, individuals serving sentences of less than three years have only four hours of freedom everyday between 08.00 and 12.00 when they have to undertake all basic activities such as shopping and most appointments, including job interviews and medical appointments. However, after one month, free hours increase automatically on a monthly basis until between 2 and 10 hours are free at the weekends and during the holidays.

The size of the inclusion and exclusion zones monitored by GPS technologies is another aspect of regime intensity. The greater the area from which wearers are 
excluded or the smaller the inclusion zone, the more intense the regime. Other factors may also have a bearing on regime intensity including the extent to which exclusion zones include: areas usually frequented by wearers and/or cover areas which contain facilities and services that they would normally access. Similarly, individuals may be able to move freely within a City, but if the City is not their usual place of residence, regime intensity is likely to be greater. The intensity of the regime may also be more keenly felt if it is a complex web of geographic areas which should and should not be accessed and if 'near misses' are made more likely. For example, when individuals are excluded from a whole area of a City but given a narrow corridor (a main road or railway line) through it so that they are able to travel between home and the City centre. In such circumstances, the complexity of the requirements and the potential for near misses, leading to allegations of non-compliance, are increased.

Two aspects of EM regimes found in one or more of our jurisdictions have the potential to loosen the 'grip' of EM. One, in Belgium, individuals serving sentences on EM are eligible for 36 hours of time without monitoring per month. Two, support is an important mechanism for ameliorating the anxieties which can result from being subject to EM. This support is most often required during monitoring hours, i.e. overnight. Our jurisdictions have different structures to support wearers. In England, support is available via a monitoring centre 24/7. Belgium also has a monitoring centre model but only a skeleton staff is deployed overnight. In addition, EM case managers and Justice Assistants provide support, but only during office hours. In the Netherlands, support is primarily provided by probation services during office hours. Outside of these hours, wearers can contact the control centre which has an on-call probation officer but they deal only with violations and breaches.

\section{Intrusiveness of regimes}

EM is unique in criminal justice because the sanction it monitors is usually served in the private domestic sphere (Hucklesby, 2009). At a minimum, EM requires at least one visit to individuals' homes to install equipment and usually a second visit to remove the equipment. Yet, it may require or entail many more 'contact' events throughout orders. Just as important as actual contacts may be the knowledge that authorities have the right/responsibility to make contact and to enter wearers' registered address. Although contacts are made only with wearers themselves, they inevitability encroach upon the privacy of other household members and/or may be visible to neighbours. This section discusses how intrusive EM regimes are by comparing the level of mandatory contact between wearers and the authorities, with particular focus on the extent to which it intrudes upon and potential disrupts their daily life and those living with them.

Contact events can take two main forms - telephone calls and visits. Telephone calls can be initiated by wearers or probation/monitoring centre staff. In Belgium, decisions to contact wearers by phone are taken by Justice Assistants following 
non-compliance events and phone calls do not usually take place at night. In England, phone calls can be made at any time during the curfew period and are initiated automatically by alerts following non-compliance. In the Netherlands, monitoring officers respond to alerts and probation officers only become involved if the problem is not resolved.

Visits to monitored addresses are an integral part of EM. They always take place at the start of orders to install the equipment and when necessary during the order to check or change equipment and investigate non-compliance. In Belgium, unannounced visits take place during curfew hours but never at night and Justice Assistants have the discretion to visit but rarely do. In England, 'routine' visits to check equipment, etc. must take place between the start of curfews and midnight. Visits to investigate alleged non-compliance may happen at any time during curfew periods. There is no requirement to inform wearers in advance, although they may expect a visit because of initial conversations with the monitoring centre but the exact timing will not be known. In the Netherlands, visits are made by monitoring officers and probation staff but not at night. Regular visits are also made to wearers' workplaces and homes by supervising probation officers. In all jurisdictions, other household members may answer the door and will be asked about the wearers' whereabouts if wearers are not in. This is one example of the involvement of household members in EM.

Initial visits to install RF equipment and any subsequent visits to check or change equipment require staff to 'range' equipment, i.e. ensure that signals are available throughout the property. Consequently, staff are required to go into every part of properties occupied by wearers to avoid blind spots. This is highly intrusive, increasing the 'depth' and 'breadth' of EM and, for those with no previous experience of EM, may be entirely unexpected. Efforts may be made to put equipment out of sight or out of reach of children or visitors, but this may not be always possible given that a good quality constant signal is required.

\section{Non-compliance and breach}

So far, this paper has discussed the elements which frame EM regimes in our three jurisdictions. In this section, we examine the framework of sanctions for noncompliance. The possibility of imprisonment is always present for individuals subject to EM and serves as the ultimate sanction for non-compliance. As Crewe (2009, 2011) observes, the ever present possibility of being sanctioned for breach (hard power) supports and reinforces the softer forms of power imposed by other aspects of regimes. Wearers are required to comply, but if this self-regulation fails, then the coercive power of sanctions is operationalised.

The foundation of the power derived from breach procedures is as much about what individuals believe to be the likelihood of being caught and the perceived outcome as actual practice. Data are limited on the outcomes of breach action but in most cases, imprisonment is at least a possibility, is deemed to be probable by wearers and is a strong influence on compliance (Hucklesby, 2009). Consequently, 
the threat of imprisonment is always present and is a strong source of 'grip' on wearers.

The perceived effectiveness of the technologies result in high expectations that non-compliance events will be discovered (Hucklesby, 2009). In addition, the concrete evidence of breach reduces the discretion inherent in enforcement decisions relating to other types of community sanctions. Consequently, the potential for violations to be uncovered and sanctioned is higher for EM than other community sanctions, thereby representing a greater weight on wearers (Hucklesby, 2009). The frequency of contact initiated by wearers in relation to non-compliance events suggests high levels of anxiety about the potential of being sanctioned for breach (Hucklesby and Holdsworth, 2016; Vanhaelemeesch, 2015).

Despite EM equipment providing clear evidence of violations, taking breach action remains discretionary. The leeway afforded to staff varies in our jurisdictions. In England, discretion is limited by strict breach policies (HM Prison and Probation Service (HMPPS), 2018; Hucklesby, 2018). In addition, the EM providers face financial penalties if they fail to comply with contract requirements resulting in high levels of reporting to relevant authorities (Hucklesby and Holdsworth, 2016). In Belgium, monitoring officers have considerable discretion whether to report alerts and often do not (Roosen, 2018). The balance between rules and the latitude to apply the rules is a key determinant of how much 'grip' is exerted by the threat and actual enforcement of EM.

All three jurisdictions have clear breach policies, but these are not published or systemically made available to wearers (Criminal Justice Joint Inspectorate (CJJI), 2008). This leaves wearers with no clear guidance on whether leeway exists particularly in relation to time violations (missing part of curfew periods). This approach is a deliberate attempt to increase the uncertainty surrounding breach policies as a mechanism to increase compliance. The existence of different breach policies for different EM modalities increases the uncertainty for wearers adding to the power wielded over individuals and to the tightness of EM regimes.

The time violation thresholds for curfews in the three jurisdictions vary. Postconviction, breach action is taken in Belgium after four hours of absence during curfew periods compared to two hours of accumulated time violations (i.e. over multiple curfew periods) in England and as little as 20 minutes in the Netherlands. Levels of seriousness and the extent of discretionary decision-making also differ between jurisdictions. In Belgium, missing four hours of a curfew is considered to be serious and results in immediate breach. In England, violations which involve missing whole curfew periods are deemed to be serious leading to immediate breach action but missing part of a curfew is treated as less serious resulting in a warning on the first occasion. The breach processes are regulated by the type and seriousness of the violations in Belgium and England and are routinised with little discretionary decision-making for all groups except those serving three years or over in Belgium. By contrast in the Netherlands, probation staff have much more discretion and responses to violations are based on the perceived risk posed by wearers. 


\section{Concluding comments}

Using rates of EM use, England would be the most punitive followed by Belgium and the Netherlands. However, a more in-depth analysis of the design of the legal and policy framework has painted a different and more nuanced picture. Four areas - equipment, intensity, intrusiveness and non-compliance/breach policies were used to compare EM regimes. These enabled length, breadth, weight and depth of EM regimes to be assessed and compared within and between jurisdictions and conclusions to be drawn about their 'tightness'. Figure 1 summarises the elements of the regimes which comprise each of the four dimensions of tightness as well as demonstrating the overlapping and complex interrelationships between them.

Our analysis enabled similarities and differences to be identified in how EM regimes are designed in the three jurisdictions. It showed that elements of the regimes in each jurisdiction pull in different directions - some are designed to 'tighten' the grip of EM whilst others aim to 'loosen' it. On the basis of our analysis, suggesting that England is the most punitive user of EM of our three jurisdictions is misleading. It uses GPS devices less, restricts the length of time individuals can be subject to EM more and has the least restrictive curfew hours at the beginning of orders of our three jurisdictions. It is also the only jurisdiction to provide 24/7 support to wearers which is a mechanism which is designed, in part, to loosen the grip of EM. By contrast, the Netherlands uses GPS devices more than the other jurisdictions, EM can be deployed for longer periods and technically for life and support is provided during office hours only but its rate of use is well below the other two jurisdictions. The fact that EM is an integral part of probation is designed to loosen the grip of EM but it also results in the boundaries between EM and probation being blurred, thereby potentially tightening its grip.

The second reason for suggesting that ranking jurisdictions on the basis of rates of use alone is too simplistic is that EM is implemented in diverse ways, with differences in tightness as great within jurisdictions as between jurisdictions. For example, Belgium has the most restrictive use of EM in its deployment to monitor 24 hour curfews pre-trial. By contrast, Belgium restricts the time on EM whilst under an autonomous sentence to 12 months. Pre-trial use of EM is less strictly regulated than post-conviction use in all three jurisdictions. The complexity we have uncovered demonstrates that whilst rates of EM use (and probably other community sentences) are a useful starting point for comparative analysis, they can lead to misleading conclusions because they hide important differences in the design of regimes which are critical to assessing levels of punitiveness. Consequently, EM rates cannot be relied on exclusively or simply 'added on' to imprisonment rates to provide an overall picture of a country's approach to punishment, i.e. its punitiveness. We suggest instead that 'tightness' combined with quantitative measures is a useful tool for comparative penological research.

This paper suggests an alternative approach to analysing and comparing EM regimes using the four dimensions of length, depth, breadth and weight used in 
prison studies. Each one of these concepts contributes important information, but only when they are amalgamated do they provide a holistic approach to compare and assess the intended impact of EM. This approach allows for an assessment of the 'tightness' or 'grip' of the EM regime. This framework uncovered similarities and differences in the extent to which regimes were designed to impact upon, and disrupt, the everyday lives of wearers in the three jurisdictions as well as drawing out the nuances in approach within and between jurisdictions. We found differences in the legal maximum time individuals can be subject to EM from 12 months to life. At its deepest, EM is used to monitor home confinement for 24 hours a day resulting in individuals being completely reliant on others for their basic needs. More commonly, however, it is designed to deprive individuals of 'leisure time' whilst minimising the impact on 'basic' and educational/employment activities. Here too, we uncovered a continuum from 'deep-end' EM in Belgium where only four hours of freedom is permitted between 08.00 and 12.00 for those who do not work to 'shallower-end' EM in England where curfew hours are routinely overnight for no more than 12 hours. We found differences too in terms of breadth. For example, some forms of EM require greater involvement from others to cater for the basic needs of wearers. More frequent and unannounced telephone calls and visits in some jurisdictions are more likely to impact upon the lives of those living with wearers. The penetration of formal criminal justice agencies into the lives of those subject to EM also varied. Standalone uses of EM usually result in less penetration than those which routinely involve probation services. Generally, however, little thought appears to have been given to the impact of EM regimes on others by policy makers. Any impacts on them are largely unintended consequences of other aspects of regime design. Therefore, they are most appropriately documented by asking those subject to EM and, their significant others, about their experiences (Vanhaelemeesch, 2015).

The third element of 'tightness', weight, is the psychological burdens produced by EM. We found that some aspects of EM were designed to add 'weight' and that these were often shared across jurisdictions. For example, authorities have powers to contact wearers by phone or visit them at home often without prior warning and the opaqueness of breach policies result in uncertainty about when enforcement action might be taken. Importantly, aspects of EM regimes are also designed to reduce 'weight'. Access to support and advice either via monitoring centres or probation staff is a mechanism for reducing levels of anxiety linked to EM thereby decreasing weight. Our jurisdictions to a greater or lesser extent provided avenues for support but differences existed in the accessibility of these services. The provision of support also provides an example of how one policy can have contradictory effects on the same or different aspects of tightness. For example, the integral involvement of probation services in EM in the Netherlands might simultaneously reduce the 'weight' of EM by providing support but increase it because enforcement decision-making is more discretionary and less certain. It might also broaden the reach of EM because there is an expectation of active engagement in other aspects of probation supervision. 
In conclusion, 'tightness' is multi-dimensional. It is indeed analogous to a web as Crewe (2011) suggested but it impacts on individuals' lives in multiple ways and not only in relation to 'weight'. Our expanded concept of 'tightness', with its constituent parts of length, depth, breadth and weight, captures more fully the complexities of EM. It, therefore, provides a useful framework for analysing the design of EM (and other community sanction) regimes as well as comparing regimes both within and between jurisdictions resulting in a more nuanced and realistic picture to emerge. There are gaps in our analysis which can only be filled by studies of the lived experiences of those subject to EM. Equally, however, there are gaps in studies which fail to discuss the design of regimes which shape how they are experienced. Tightness provides an analytical tool with which to better understand both. It may not be possible or even desirable to make accurate assessment of countries' punitiveness (Crewe, 2015; Pease, 1994) but such endeavours will better reflect reality if 'tightness' and rates of use are the basis of analysis.

\section{ORCID iDs}

Anthea Hucklesby (DD https://orcid.org/0000-0001-6366-0442

Kristel Beyens (D) https://orcid.org/0000-0001-7073-637X

\section{Notes}

1. We use the term community sanctions and measures to include pre-trial measures (bail), community sentences and early release licences. We use community sanctions thereafter to include the use of EM at all of these stages of the criminal justice process.

2. Hereafter referred to as England.

3. Population figures are taken from World Prison Brief (Walmsley, 2018).

\section{References}

Aebi MF, Delgrande N and Yann M (2015) Have community sanctions and measures widened the net of the European criminal justice systems? Punishment \& Society 17(5): 575-597.

Aebi MF, Hashimoto Y and Tiago M (2019) Probation and Prisons in Europe, 2018: Key Findings from the SPACE Reports. Strasbourg, France: Council of Europe.

Aebi MF and Tiago MM (2019) Prisons in Europe, 2018: Key Findings from the SPACE 1 Report. Strasbourg, France: Council of Europe.

Beyens K and Roosen M (2016) Electronic Monitoring in Belgium. Available at: http:// 28uzqb445tcn4c24864ahmel.wpengine.netdna-cdn.com/files/2016/06/EMEU-

Electronic-monitoring-in-Belgium.pdf (accessed 18 March 2020).

Boone M, Van der Kooij M and Rap S (2016) Electronic Monitoring in the Netherlands. Available at: http://28uzqb445tcn4c24864ahmel.wpengine.netdna-cdn.com/files/2016/ 06/EMEU-Electronic-monitoring-in-the-Netherlands.pdf (accessed 18 March 2020).

Boone M, Van der Kooij M and Rap S (2017) The highly reintegrative approach of EM in the Netherlands. European Journal of Probation 9(1): 47-61. 
Cavadino M and Dignan J (2006) Penal Systems: A Comparative Approach. London, UK: Sage.

Cohen S (1985) Visions of Social Control. Cambridge, UK: Polity Press.

Crewe B (2009) The Prisoner Society: Power, Adaptation and Social Life in an English Prison. Oxford, UK: Oxford University Press.

Crewe B (2011) Depth, weight, tightness: Revisiting the pains of imprisonment. Punishment \& Society 13(5): 509-529.

Crewe B (2015) Inside the belly of the penal beast: Understanding the experience of imprisonment. International Journal for Crime, Justice and Social Democracy 4(1): 50-65.

Criminal Justice Joint Inspectorate (CJJI) (2008) A Complicated Business: An Inspection of Electronic Monitoring, HMI Probation, HMI Constabulary and HMI Courts Administration, Joint Inspection by HMI Probation, HMI Court Administration and HMI Constabulary. Manchester, UK: HMIP.

Downes D (1988) Contrasts in Tolerance: Post-War Penal Policy in the Netherlands and England. Oxford, UK: Clarendon Press.

Downes D (1992) The case for going Dutch: The lessons of post-war penal policy. The Political Quarterly 63(1): 12-24.

Durnescu I (2011) Pains of probation: Effective practice and human rights. International Journal of Offender Therapy and Comparative Criminology 55(4): 530-545.

Gacek J (2019) Stuck in the carceral web: Prisoners' experiences of electronic monitoring. Criminology Encounters 2(1). Available at: www.criminologicalencounters. org/index.php/crimenc (accessed 18 March 2020).

Hayes D (2015) The impact of supervision on the pains of community penalties in England: An exploratory study. European Journal of Probation 7(2): 85-102.

HM Prison and Probation Service (HMPPS) (2018) (2014) Enforcement of community orders and suspended sentence orders, PI 06/2014. Available at: www.justice.gov.uk/ offenders/probation-instructions/pi-archive-2014 (accessed 18 March 2020).

Hucklesby A (2008) Vehicles of desistance? The impact of electronically monitored curfew orders. Criminology \& Criminal Justice 8(1): 51-71.

Hucklesby A (2009) Understanding offenders' compliance: A case study of electronically monitored curfew orders. Journal of Law and Society 36(2): 248-271.

Hucklesby A (2018) Non-compliance and the breach process in England and Wales. In Boone M and Maguire N (eds) The Enforcement of Offender Supervision in Europe: Understanding Breach Processes. London, UK: Routledge, pp.134-151.

Hucklesby A, Beyens K, Boone M, et al. (2016) Creativity and effectiveness in the use of electronic monitoring: A case study of five European jurisdictions. Available at: http:// 28uzqb445tcn4c24864ahmel.wpengine.netdna-cdn.com/files/2016/06/EMEUCreativity-and-effectiveness-in-EM-Long-version.pdf (accessed 18 March 2020).

Hucklesby A and Holdsworth E (2016) Electronic monitoring in England and Wales. Available at: http://28uzqb445tcn4c24864ahmel.wpengine.netdna-cdn.com/files/ 2016/06/EMEU-Electronic-monitoring-in-England-and-Wales.pdf (accessed 18 March 2020).

Hudson K and Jones T (2016) Satellite tracking of offenders and integrated offender management: A local case study. The Howard Journal of Crime and Justice 55(1-2): 188-206. 
King RD and McDermott K (1995) The State of Our Prisons. Oxford, UK: Clarendon Press.

Matthews R (2005) The myth of punitiveness. Theoretical Criminology 9(2): 175-201. McNeill F (2018) Pervasive Punishment: Making Sense of Mass Supervision. Bingley, UK: Emerald Publishing Limited.

McNeill F and Beyens K (eds) (2013) Offender Supervision in Europe. Basingstoke, UK: Palgrave Macmillan.

Ministry of Justice (MoJ) (2018) Offender Management Statistics Quarterly: January to March 2018. London, UK: MoJ.

Nellis M (2013) Surveillance, stigma and spatial constraint: The ethical challenges of electronic monitoring. In: Nellis M, Beyens K and Kaminski D (eds) Electronically Monitored Punishment: International and Critical Perspectives. London, UK: Routledge, pp.193-210.

Payne BK and Gainey RR (1998) A qualitative assessment of the pains experienced on electronic monitoring. International Journal of Offender Therapy and Comparative Criminology 42(2): 149-163.

Pease K (1994) Cross-national imprisonment rates: Limitations of method and possible conclusions. The British Journal of Criminology 34: 116-130.

Roosen M (2018) Using technology to punish. An empirical study of the work of the electronic monitoring officers from a structuration theory approach. Unpublished $\mathrm{PhD}$, Vrije Universiteit Brussel, Brussel.

Shammas VL (2014) The pains of freedom: Assessing the ambiguity of Scandinavian penal exceptionalism on Norway's Prison Island. Punishment \& Society 16(1): $104-123$.

Sykes G (1958) The Society of Captives: A Study of a Maximum-Security Prison. Princeton, NJ: Princeton University Press.

Vanhaelemeesch D (2015) De Beleving Van Elektronisch Toezicht in Vergelijking Met de Gevangenisstraf. Den Haag, the Netherlands: Boom Uitgevers.

Vanhaelemeesch D and Vander Beken T (2014) Between convict and ward: The experiences of people living with offenders subject to electronic monitoring. Crime, Law and Social Change 62(4): 389-415.

Vanhaelemeesch D, Vander Beken T and Vandevelde S (2014) Punishment at home: Offenders' experiences with electronic monitoring. European Journal of Criminology 11: $273-287$.

Walmsley R (2018) World Prison Population List. 12th edition. London, UK: Institute for Criminal Policy Research (ICPR).

Anthea Hucklesby is a professor of Criminal Justice and Pro-dean for Research and Innovation at the University of Leeds, UK. Her recent research focuses on the use of EM as is part of a wider programme of work on community sanctions and measures from pre-trial to post-release. She led the European Commission funded project 'Creativity and effectiveness in the use of EM as an alternative to custody' and is currently working on the use of EM in youth justice. She created and leads the 'Tracking People' network which focuses on the use of tracking devices in 
numerous domains including dementia care, mental health, immigration and terrorism (http://trackingpeople.leeds.ac.uk).

Kristel Beyens is a professor of Penology and Criminology and head of the Department of Criminology and of the research group Crime \& Society (CRiS) of the Vrije Universiteit Brussel. Her research focuses on contemporary evolutions in punishment with special attention for penal decision-making and the implementation of prison sentences and community punishment in a cultural, organizational and social context. She has published on a.o. prison overcrowding and penal policies, sentencing and penal decision-making with regard to release, breach and recall, (transnational) imprisonment and electronic monitoring.

Miranda Boone is a professor of Criminology and Comparative Penology at the Institute of Criminal Law and Criminology at Leiden University, the Netherlands. Her research focuses on sentencing and (the execution of) punishment. She uses both a social scientific and normative approach to study sentencing decisionmaking processes. She has published on sentencing, (transnational) imprisonment, probation and community punishment from both a national and international perspective. 